\title{
Single-incision laparoscopic colectomy without using special articulating instruments: an initial experience
}

\author{
Atthaphorn Trakarnsanga, Thawatchai Akaraviputh*, Pakpong Wathanaoran, Chainarong Phalanusitthepha, \\ Asada Methasate and Vitoon Chinswangwattanakul
}

\begin{abstract}
Background: Single-incision laparoscopic colectomy (SILC) was introduced as a novel minimally invasive technique. The benefits of this technique include reducing number of the incision and cosmetic improvement. Unlike the conventional laparoscopic colectomy, majority of previously reported SILC need to be performed using special curved or articulated instruments. The purpose of this study is to demonstrate our initial experience of SILC, which could be performed using the standard laparoscopic instruments.
\end{abstract}

Material and methods: Retrospective review of 14 patients who underwent SILC at Siriraj Hospital from May to December 2010, patient's demographic data, perioperative outcomes, early postoperative complications and pathological data were collected and analyzed.

Results: The mean age of all patients was 60 years. The most common operation with SILC was sigmoidectomy ( $\mathrm{n}$ $=9$ ), followed by right hemicolectomy $(n=2)$, left hemicolectomy $(n=1)$, anterior resection $(n=1)$, and total colectomy $(n=1)$. The trocar insertion techniques were multi-fascial incision using regular port $(n=11)$ and GeIPOINT $^{\circledR}(n=3)$. The mean operative time was 155 minutes (range 90-280) and the mean estimate blood loss was $32.1 \mathrm{~mL}$ (range 10-100). All patients were successfully operated without conversion. The mean length of hospital stay was 9 days (range 5-20). There was no mortality. The pathological results revealed colorectal cancer ( $\mathrm{n}$ $=12$ ), neoplastic polyp $(n=1)$ and Familial adenomatous polyposis (FAP) $(n=1)$. The mean number of lymph nodes retrieval was 16.6 (range 3-34).

Conclusion: SILC can successfully and safely be performed with standard laparoscopic instruments. This technique might be an alternative procedure to conventional laparoscopic colectomy with better cosmetic result.

Keywords: Minimally invasive surgery, Single-incision laparoscopic colectomy, Laparoscopic colectomy, Colorectal neoplasms

\section{Background}

Recently, minimally invasive surgery for colon cancer treatment became more popular. This approach provided better short-term advantages, such as less postoperative pain, rapid return of bowel function, shorter hospitalization and rapidly returns to normal activity, compare to conventional open method. However, there are no differences in terms of post-operative complications and

\footnotetext{
* Correspondence: sitak@mahidol.ac.th
Minimally Invasive Surgery Unit, Division of General Surgery, Department of

* Correspondence: sitak@mahidol.ac.th Surgery, Faculty of Medicine Siriraj Hospital, Mahidol University, Bangkok 10700, Thailand
}

(c) 2011 Trakarnsanga et al; licensee BioMed Central Ltd. This is an Open Access article distributed under the terms of the Creative Commons Attribution License (http://creativecommons.org/licenses/by/2.0), which permits unrestricted use, distribution, and reproduction in any medium, provided the original work is properly cited.

mortality rate compare to conventional open method [1-4]. Moreover, the long-term oncological outcome is not significantly different between both methods [5-8].

In 1992, Pelosi et al. [9] firstly reported the successful technique of single-incision laparoscopic surgery (SILS) which minimizes the number of port from multiple to only one operative port. In the beginning, this technique was used for simple procedures, such as cholecystectomy, appendectomy and nephrectomy [10-12]. Subsequently, SILS was applied to more complex operations, for example, sleeve gastrectomy and colectomy $[13,14]$. The benefits of SILS include reduce number of the 
incisions, less postoperative pain [11], improve cosmetic outcome $[10,15]$ and decrease incidence of incisional hernia [14].

After Leroy et al. [16] reported the feasibility of Single-incision laparoscopic colectomy (SILC) in experimental model in 2008, several case series of SILC were widely published. However, SILS has several disadvantages such as the handling of both straight instruments in parallel with the laparoscope through a small incision decreases the freedom of motion for the surgeon and complicates the holding of the laparoscope for the assistant [15]. As a result of limitation of triangulation, majority of reports used special articulating instruments to overcome this problem [17-19]. In this study, we present our initial experiences of SILC successfully perform by using standard non-articulating laparoscopic instruments.

\section{Material and methods}

After the Institutional Review Board approved this study, retrospective review from our prospective maintained database from May to December 2010 was performed. Fourteen SILC procedures were identified, all of these operations performed at Minimally Invasive Surgery Unit, Division of General Surgery, Department of Surgery, Faculty of Medicine Siriraj Hospital. Age, gender, body mass index (BMI), operative time (OPT), estimated blood loss (EBL), early post-operative complications, length of hospital stay (LHS) and pathological data were collected and analyzed.

\section{Surgical Technique}

We used two trocar insertion techniques; multi-facial incision $(\mathrm{n}=11)$ and GelPOINT ${ }^{\circledR}(\mathrm{n}=3$, Applied Medical, Rancho Santa Margarita, CA). For multi-fascial incision, we started with making a small 4-5 cm midline incision. Division of skin and subcutaneous tissue were made except anterior abdominal fascia. Pnuemoperitoneum was created with closed technique by puncturing with the Veress needle awaiting adequate pressure at 15 $\mathrm{mmHg}$. A 12-mm. trocar was introduced to abdominal cavity for a 10-mm., 30-degree camera (Endoeye $\mathrm{e}^{\mathrm{TM}}$, Olympus comp., Tokyo, Japan). Two regular 5-mm. ports were placed at the upper and lower end of incision (Figure 1). In all procedures, three standard non-articulating instruments were used (one bowel grasper, one endohook or vessel sealing device and another one for endoscope) (Figure 2). Median to lateral approach was applied for all operations. The main artery was dissected, double clipped and transected. After the pathological segment of colon was completely mobilized, the pneumoperitoneum was removed. Completion incise of abdominal wall sheath was performed. A small wound retractor (ALEXIS wound retractor S, Applied Medical,

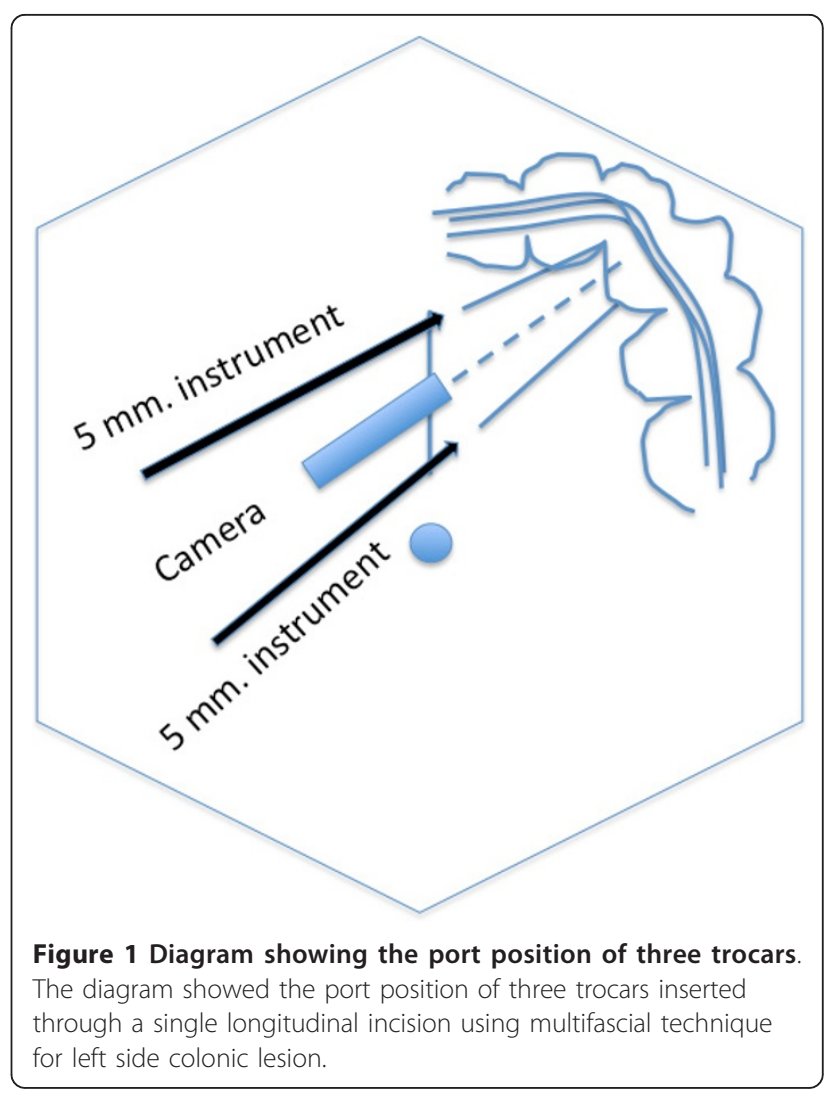

Santa Margarita, CA, USA) was applied for wound protection. The specimen was extracted through the midline incision. Colonic resection and making anastomosis were performed extra-peritoneal cavity by double staples or hand-sew technique.

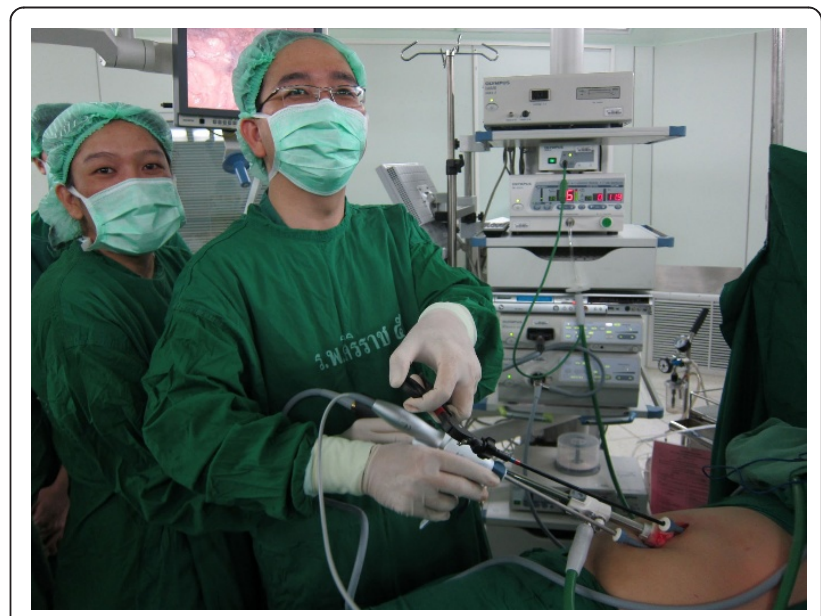

Figure 2 Picture demonstrating the position of the surgeon The picture demonstrated the position of the surgeon and an assistant on right side of the patient performing SILC left half colectomy. 


\section{Results}

Fourteen patients were included to this study. The mean age was 60 years (range 23-90). Seven patients were female. The mean BMI was $25.2 \mathrm{~kg} / \mathrm{cm}^{2}$ (range 17.336.1). Nine patients underwent SILC for sigmoidectomy, two for right hemicolectomy and each one for left hemicolectomy, anterior resection and total colectomy. The mean OPT was 155 minutes (range 90-280) and the mean EBL was $32.1 \mathrm{~mL}$ (range 10-100). Extracorporeal anastomosis was created using double staplers $(n=9)$ or hand-sewn technique $(\mathrm{n}=5)$. There was no conversion in all procedures. The mean LHS was 9 days (range 5-20). There were no postoperative complication and mortality in this study. The pathological results revealed colorectal cancer $(n=12)$, neoplastic polyp $(n=1)$ and FAP $(\mathrm{n}=1)$. The mean number of lymph nodes harvested was 16.6 (range $3-34$ ).

\section{Discussion}

After Jacobs [20] firstly reported successfully laparoscopic colectomy in 1990. Varieties of minimally invasive surgical technique for colorectal surgery were introduced, including total laparoscopic colectomy (TLC), Hand-assisted laparoscopic colectomy (HALC), Single incision laparoscopic colectomy (SILC) and Robotic-assisted laparoscopic colectomy (RALC). Each procedure has different benefits as well as limitations. Most surgeons are now convinced of the benefits of the laparoscopic approach in colorectal surgery [1-4]. While advantages of laparoscopic surgery include shorter postoperative hospital stay, early return of bowel function, and decreased complications. Disadvantages of TLC are multiple-port sites in the abdomen and an additional incision for removing the specimen. HALC is suitable in complex procedures and bulky tumor [21]. Moreover, the learning curve is shorter than TLC [21]. For RALC, the most benefit of this approach is total mesorectal excision for rectal cancer. The limitations of RLAC are the restriction of the surgical field and high operative cost.

SILC is the new emerging technique in the past two years. The initial applications of SILS in gastrointestinal surgery were appendectomy and cholecystectomy. Currently, a plenty of reports proposed of safety and feasibility of this technique [14,15,17-19]. In addition, SILC seems to provide improvement in cosmetic result with potential decreased pain by reducing the number of incision $[15,22]$ and possible fewer incidence of postoperative incisional hernia[14]. This technique may generate lower risk of port-side metastasis in malignant cases (only one incision). Disadvantages of SILC are restriction of movement, limitation of triangulation and the axis of camera parallel to the instruments. All of these problems need to be corrected by using the special camera (30 or 45 degree or flexible scope) or the special articulating instruments.

From our series, we started to perform SILC in the selected patients who had an early stage of colon carcinoma. We used two techniques for SILC, one is using GelPOINT $^{\circledR}$ and the other is multi-fascial puncture technique. Most of the cases, we used the later technique because of the simplification of the instrument and lower cost. The limitation of the movement is not great different by the two techniques. We overcome the restriction of the angle by using the 30-degree camera. The dissection was started from medial to lateral approach. One of the reasons using this approach is natural adhesion of the colon to lateral abdominal wall can help us to hold the colon. In addition, familiarity of anatomic landmark same as traditional total laparoscopic approach is another reason.

We used conventional straight laparoscopic instruments such as endohook and bowel grasper. Some cases, we used vessels sealing instruments for soft tissue dissection. Surprisingly, SILC for right half colectomy and sigmoidectomy with conventional straight instruments were not a difficult procedure. Varieties of the laparoscopic procedures can be performed successfully without conversion and with minimal intraoperative blood loss. The operative time is acceptable for the learning period. The lymph nodes were adequately retrieved. One patient needs long hospital stay because of his underlying disease without any operative complications.

\section{Conclusion}

In conclusion, SILC can be successfully and safely performed using standard laparoscopic instruments. When compare to standard laparoscopic colectomy, the potential advantages of the SILS include reduction in incision, decrease postoperative pain, and improve cosmetics. This technique can be done as an alternative method to conventional laparoscopic approach with comparable outcomes.

\section{Acknowledgements}

We would like to acknowledge to Dr. Nguyen Hoang Bac and Dr. Nguyen Huu Thinh from University of Medical Center, Ho Chi Minh City, Vietnam for their excellent demonstration in the multi-fascial insertion technique. In addition, we would like to thank you to Dr. Suthinee Ithimakin for language correction.

\section{Authors' contributions}

AT, TA and VC were the surgeon who performed the SILC operation. TA and AT originated the idea and drafted up the manuscript. AM, PW and CP participated in the operation. TA and PW collected and analyzed the data. TA critically reviewed and edited the manuscript. All authors read and approved the final manuscript. 


\section{Competing interests}

The authors declare that they have no competing interests.

Received: 15 August 2011 Accepted: 7 December 2011

Published: 7 December 2011

\section{References}

1. Lacy AM, Garc lia-Valdecasas JC, Delgado S, et al: Laparoscopy assisted colectomy versus open colectomy for treatment of non-metastatic colon cancer: a randomised trial. Lancet 2002, 359(9325):2224-9.

2. Nelson H, COST Study Group: A comparison of laparoscopically assisted and open colectomy for colon cancer. N Engl J Med 2004, 350(20):2050-9.

3. Veldkamp R, Kuhry E, Hop WC, et al: Laparoscopic surgery versus open surgery for colon cancer: short-term outcomes of a randomized trial. Lancet Oncol 2005, 6:477-84.

4. Guillou PJ, Quirke P, Thorpe H, et al: Short-term endpoints of conventional versus laparoscopic-assisted surgery in patients with colorectal cancer (MRC CLASICC trial): multicentre, randomized controlled trial. Lancet 2005, 365:1718-26.

5. Jayne DG, Guillou PJ, Thorpe H, et al: Randomized trial of laparoscopicassisted resection of colorectal carcinoma: 3-year results of the UK MRC CLASICC Trial Group. J Clin Oncol 2007, 25(21):3061-8.

6. Fleshman J, Sargent DJ, Green E, et al: Laparoscopic colectomy for cancer is not inferior to open surgery based on 5-year data from the COST Study Group trial. Ann Surg 2007, 246(4):655-62.

7. Lacy AM, Delgado S, Castells $A$, et al: The long-term results of a randomized clinical trial of laparoscopy-assisted versus open surgery for colon cancer. Ann Surg 2008, 248(1):1-7.

8. Buunen M, Veldkamp R, Hop WC, et al: Survival after laparoscopic surgery versus open surgery for colon cancer: long-term outcome of a randomised clinical trial. Lancet Oncol 2009, 10(1):44-52.

9. Pelosi MA, Pelosi MA: Laparoscopic supracervical hysterectomy using a single-umbilical puncture (mini-laparoscopy). J Reprod Med 1992, 37(9):777-84.

10. Ates O, Hakguder G, Olguner M, Akgur MA: Single-port laparoscopic appendectomy conducted intracorporeally with the aid of a transabdominal sling suture. J Pediatr Surg 2007, 42(6):1071-4

11. Bresadola F, Pasqualucci $A$, Donini A, et al: Elective transumbilical compared with standard laparoscopic cholecystectomy. Eur J Surg 1999, 165:29-34

12. Desai MM, Rao PP, Aron M, et al: Scarless single port transumbilical nephrectomy and pyeloplasty: first clinical report. BJU Int 2008, 101:83-8.

13. Saber AA, El-Ghazaly TH, Ellan A: Single-incision transumbilical laparoscopic sleeve gastrectomy. J Laparoendosc Adv Surg Tech A 2009, 19(6):755-8.

14. Bucher P, Pugin F, Morel P: Single port access laproscopic right hemicolectomy. Int J Colorectal Dis 2008, 23:1013-6.

15. Leblanc F, Champange BJ, Augestad KM, et al: Single incision laparoscopic colectomy: technical aspects, feasibility, and expected benefits. Diagn Ther Endosc 2010, 913216, Epub 2010 May 30.

16. Leroy J, Cahill RA, Peretta S, Marescaux J: Single port sigmoidectomy in an experimental model with survival. Surg Innov 2008, 15(4):260-5.

17. Boni L, Dionigi G, Cassinotti E, et al: Single incision laparoscopic right colectomy. Surg Endosc 2010, 24(12):3233-6.

18. Vestweber B, Alfes A, Pual C, Haaf F, Vestweber KH: Single-incision laparoscopic surgery: a promising approach to sigmoidectomy for diverticular disease. Surg Endosc 2010, 24(12):3225-8.

19. Diana M, Dhumane P, Cahill RA, et al: Minimal invasive single-site surgery in colorectal procedures: Current state of the art. J Minim Access Surg 2011, 7(1):52-60

20. Jacobs M, Verdeja JC, Goldstein HS: Minimally Invasive colon resection (laparoscopic colectomy). Surg Laparosc Endosc 1991, 1:144-50

21. Cima RR, Pattana-arun J, Larson DW, et al: Experience with 969 minimal access colectomies: The role of hand-assisted laparoscopy in expanding minimally invasive surgery for complex colectomies. J Am Coll Surg 2008, 206(5):946-50.

22. Chambers W, Bicsak M, Lamparell M, Dixon A: Single-incision laparoscopic surgery (SILS) in complex colorectal surgery: a technique offering potential and not just cosmesis. Colorectal Dis 2011, 13(4):393-8. doi:10.1186/1477-7819-9-162

Cite this article as: Trakarnsanga et al:: Single-incision laparoscopic colectomy without using special articulating instruments: an initial experience. World Journal of Surgical Oncology 2011 9:162.

\section{Submit your next manuscript to BioMed Central and take full advantage of:}

- Convenient online submission

- Thorough peer review

- No space constraints or color figure charges

- Immediate publication on acceptance

- Inclusion in PubMed, CAS, Scopus and Google Scholar

- Research which is freely available for redistribution

Submit your manuscript at www.biomedcentral.com/submit
Biomed Central 